\title{
Justicia, democracia y pluralidad
}

\author{
Ambrosio Velasco
}

Luis Villoro, Tres retos de la sociedad por venir.

México, Siglo XXI, 2009. 80 pp.

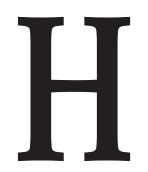

ace un par de años, Luis Villoro me hizo favor de hacer unos comentarios a mi libro Multiculturalismo y republicanismo (México, Siglo XXI, 2007) que se publicaron en el periódico comunitario de la Facultad de Filosofía y Letras, Metate. En esos comentarios, además de sugerentes críticas sobre mi insistencia en las virtudes del republicanismo, invitaba a continuar y desarrollar más ampliamente la discusión sobre democracia y multiculturalismo. Posteriormente, Luis Villoro amplió sus puntos de vista sobre comunitarismo, republicanismo y multiculturalismo en un artículo publicado en el número 19 de Theoría. En días recientes Luis Villoro me invitó gentilmente a presentar su nuevo libro en el Aula Magna Fray Alonso de la Veracruz de la Facultad de Filosofía y Letras de la UNAM. Le agradezco mucho esta honrosa oportunidad de continuar y ampliar el diálogo sobre estos temas de común interés que refieren a problemas centrales de la filosofía y de nuestro mundo actual.

El nuevo libro de Luis Villoro es un desarrollo sintético y focalizado de trabajos y discusiones previos, particularmente de su libros Los retos de la sociedad por venir (FCE, 2007) y Estado plural, pluralidad de culturas (UNAM/Paidós, 1998). Está compuesto por tres ensayos que son expresión paradigmática de la filosofía iberoamericana, que según Gaos, se caracteriza por tener una preocupación pedagógica y política dirigida a actuar y transformar las conciencias y actitudes de su público y, de esta manera, transformar la realidad social y política. Por tal virtud, el libro que comentamos es un ejercicio del "uso público de la razón" en el sentido kantiano. Además tiene otra característica, también distinta del pensamiento iberoamericano: su autor, Luis Villoro, se sitúa ante la realidad específica, propiamente latinoamericana, diferente a la europea, o a la norteamericana. Desde esta situación, Villoro propone una perspectiva distinta a la referida por autores de aquellas culturas como Rawls o Habermas, para reflexionar sobre tres conceptos que refieren a tres grandes problemas de nuestras sociedades: la justicia, la democracia y la pluralidad cultural. 
La vía, o perspectiva que propone, parte de la realidad inmediata que experimentamos en México y en muchas regiones de Latinoamérica, Asia y África: la profunda injusticia, la ausencia de democracia y el desconocimiento de la pluralidad cultural.

Esta experiencia que Luis Villoro comparte con la mayoría de los habitantes de México y Latinoamérica, lo motiva a proponer una aproximación o "vía" negativa, que consiste no en partir de los postulados de un principio racional de justicia basado en un consenso supuesto (Rawls) o propuesto (Habermas), o asumido a priori (Apel), sino, por el contrario, en la experiencia de la injusticia; derivada de la ausencia de un consenso general, debido a la exclusión de la mayoría de los habitantes y ciudadanos de la nación, exclusión que imposibilita la verdadera vida democrática y que se origina en la falta de reconocimiento de las diversas identidades culturales de los pueblos que conforman los Estados nacionales contemporáneos.

Los tres conceptos están estrechamente entrelazados, y el problema real al que alude cada concepto, no puede superarse si no se atiende a los otros dos. No obstante, para fines analíticos y expositivos, Luis Villoro trata primero el concepto de injusticia, después el de democracia y finalmente el de pluralidad cultural.

Respecto a la injusticia, Luis Villoro considera que es ante todo vivencia o experiencia de sufrimiento de un mal o daño causado por otros, de manera injustificada, como resultado de relaciones no legítimas de poder.

El poder originalmente es capacidad para realizar los fines y deseos de las personas (poder para), pero históricamente, este afán se convierte en dominación sobre otros (poder sobre) para satisfacer los deseos propios, a costa del sufrimiento de otros. El afán de poder como dominación, se traduce pues en ejercicio de la violencia para someter a otras personas que se convierten en meros medios para la realización de los intereses o deseos de quienes detentan el poder. Este afán, o la principal pasión del hombre, según muchos filósofos de la Antigüedad tal como lo describe Trasímaco en la República, hasta Hobbes, Max Weber y Karl Schmitt.

Frente al afán de poder de la "real politik", Luis Villoro destaca la perspectiva ética y normativa (a veces llamada idealista) que como la de Sócrates propone el afán de escapar al poder, de emanciparse de las relaciones de dominación, esto es, de ejercer el contrapoder. "Podemos llamar 'contrapoder' a toda fuerza de resistencia frente a la dominación. El contrapoder se manifiesta en todo comportamiento que se defiende y resiste al poder" (p. 17).

Villoro inclusive considera que la tensión entre poder y contrapoder puede ser una manera de contemplar el sentido de la historia: "La realización paulatina que condujera a un mundo liberado en todos sus resquicios del afán universal de poder, sería una idea regulativa que daría sentido ético a nuestras acciones" (p. 19). 
La emancipación de las relaciones de dominación, causa de la injusticia, pasa por tres momentos:

1. La experiencia de la exclusión, causa de sufrimiento conjunto.

2. El juicio y denuncia sobre el carácter injusto de la exclusión.

3. La propuesta de un nuevo modelo de justicia, donde los excluidos del consenso sean incluidos y por ello cese la injusticia.

Ésta es la vía negativa hacia la justicia, negativa en cuanto se abole o suprime la injusticia a través de reducir la exclusión (se niega la negación): "La idea de injusticia a partir de la experiencia de la exclusión puede considerarse un proceso histórico real en el que pueden eliminarse progresivamente las injusticias existentes y acercarse a un orden social más justo que denunciara o al menos disminuyera las exclusiones e injusticias existentes" (p. 25).

Según Villoro, este proceso se desarrolla históricamente, primero en términos de la denuncia de exclusión por motivos étnicos (Bartolomé de las Casas y la defensa de los indios y yo agregaría con igual importancia a fray Alonso de la Veracruz); después a favor de la tolerancia religiosa (Locke) y el reconocimiento de los derechos civiles y políticos universales (Revolución francesa; Rousseau, Kant); la denuncia a la exclusión económica (Marx), y la exclusión de la misma diversidad cultural (el mismo Villoro y los multiculturalistas), constituyen las formas más recientes de exclusión.

Desde luego, el protagonista de este proceso emancipador es un sujeto moral a la par individual y colectivo que exige su reconocimiento como persona al poder que hasta entonces lo ha excluido. En este sentido, la exigencia moral de la inclusión tiene repercusiones políticas hacia la democratización del orden político. El segundo concepto es precisamente el de democracia.

Luis Villoro distingue y confronta dos concepciones de la democracia. La liberal representativa, por un lado, y la republicana comunitaria por otro. Es importante observar que Luis Villoro tiende a caracterizar conjuntamente la republicana y la comunitaria, lo cual, desde mi punto de vista, no es conveniente, pues hay importantes diferencias entre ambas.

La democracia liberal la refiere Villoro al pensamiento de John Rawls y en general a la tradición anglosajona (Locke, John Stuart Mill). Con toda razón señala que esta concepción predomina en el mundo occidental. Sus notas características son las siguientes:

- El individuo es la única persona moral.

- La sociedad no es un ente en sí, sino una asociación contractual de individuos en la que se definen derechos y libertades (negativas). 
- La sociedad política, el Estado tiene la finalidad de salvaguardar la libertad individual (paradoja hobbesiana).

- Los individuos en cuanto ciudadanos tienen un mismo conjunto de libertades y derechos que no pueden ser violados. El ámbito de su ejercicio constituye la dimensión privada de la sociedad, contrapuesta al ámbito del sector público, donde sí interviene el poder.

La concepción comunitaria (republicana) de la democracia presenta las siguientes características:

- La sociedad, la comunidad preexiste al individuo. Existe un sujeto colectivo al que pertenece el individuo.

- Los fines del individuo presuponen y se realiza en la comunidad. El interés privado está supeditado al bien común.

- Los derechos colectivos tienen prelación sobre los derechos individuales.

- En la comunidad no hay competencia sino cooperación y solidaridad.

- La justicia es el logro del bien común sin exclusiones (aunque sí sacrificio).

Ante estas dos concepciones de la democracia, Luis Villoro toma partido decididamente a favor de la segunda: "El liberalismo es una expresión, en filosofía, del individualismo moderno; el republicanismo y el comunitarismo, en cambio, expresan el proyecto futuro de una posible comunidad renovada. El futuro próximo dependerá, en gran medida, del resultado de esa alternativa, en la ética y en la política" (p. 56).

La visión liberal "ningunea" o ignora al pluralismo cultural, asumiendo una posición neutral respecto a las concepciones sustantivas del bien común que no se consideran políticamente relevantes. Por el contrario, desde la visión comunitarista o republicana, según Villoro, se procuraría adecuar las instituciones políticas y jurídicas a las características culturales de los grupos y pueblos.

Desde mi punto de vista, habría aquí que marcar una diferencia entre comunitarismo y republicanismo. El comunitarismo tendría dificultades para responder a situaciones en las que en una misma comunidad o pueblo exista una multiplicidad de tradiciones y de concepciones sustantivas del bien. Tendría que escoger entre privilegiar alguna de ellas con exclusión de las otras, o bien negar relevancia política a las diferencias culturales en aras de la imparcialidad, como recomienda el liberalismo. Frente a este dilema el republicanismo partiría de un principio de inclusión de la pluralidad, reconociendo las tensiones y conflictos que necesariamente se generan, pero 
confiando en una solución dialógica y deliberativa, propiamente política, a esos conflictos, para alcanzar consensos o bien para reconocer disensos irreductibles por el momento que tienen que negociarse y respetarse. Desde la perspectiva republicana la tarea principal de la política es precisamente procesar y acomodar consensos y disensos en el seno de la pluralidad cultural y social. Para tal fin resulta esencial el reconocimiento de autonomías locales, y el acotamiento de la jurisdicción de los poderes centrales y estatales acorde a un auténtico federalismo. Esta propuesta fue hecha originalmente por dos grandes humanistas republicanos mexicanos, Las Casas y De la Veracruz, como una solución al grave problema de la exclusión de los indígenas provocada por la conquista y dominación españolas en el siglo XVI, exclusión que se ha prolongado hasta nuestros días. Este humanismo que se origina en el siglo XVI tiene un carácter republicano y no tanto comunitarista. Como he tratado de argumentar en el libro Republicanismo y multiculturalismo (2007), así como en La persistencia del humanismo republicano en la conformación de la nación y el Estado mexicano (2009) los movimientos indígenas, como el EZLN, son los herederos y principales representantes del republicanismo que surgió en los años inmediatos a la conquista, como resultado del aprendizaje y reconocimiento de las civilizaciones originarias que hicieron humanistas como Bartolomé de las Casas y Alonso de la Veracruz, quien además de condenar como ilegítimo el dominio español, por carecer de reconocimiento de los pueblos originarios, demandaron autonomía para las repúblicas de indios frente a la Corona española.

La demanda de autonomía persistió con diferentes matices y en diversos escenarios a lo largo de la dominación colonial y se convirtió en uno de lo principales reclamos que originaron la independencia en 1808, como el propio Villoro ha documentado en su excelente libro El proceso ideológico de la revolución de Independencia, publicado originalmente en 1953. Con esto se pone en evidencia la persistencia de una preocupación intelectual fundamental de Luis Villoro por los problemas más graves de nuestra nación, y desde luego se manifiesta su inquebrantable compromiso ético y político contra la exclusión y a favor de la justicia.

Así pues, mi divergencia con Luis Villoro reside en considerar al republicanismo de origen propiamente iberoamericano y no al comunitarismo como el tipo de democracia adecuada para promover el multiculturalismo. En lo demás estoy totalmente de acuerdo, especialmente con su crítica al liberalismo y su defensa del pluralismo, tema sobre el que versa el tercer ensayo del libro.

El pluralismo es una posición ética, política y cultural contraria a la modernidad occidental en su fase actual: la globalización, que ha causado graves daños y sufrimientos: injusticias como la explotación y marginación, pobreza de la mayoría de la humanidad, deterioro del medio ambiente. Frente a esta 
situación injusta, Luis Villoro propone impulsar un orden plural que promueva el respeto a la diversidad de culturas "Se reclama entonces la libertad de cada cultura para determinar sus propios fines" y no estar sometida a la dominación de la cultura occidental moderna, caracterizada por un capitalismo que pierde sentido humano, por un poder político excluyente de la participación ciudadana, por una racionalidad científica tecnológica que vacía de sentido la vida social.

Frente a esta racionalidad de la cultura occidental moderna, existe un creciente movimiento multicultural a dos niveles: de naciones antes colonizadas frente a las metrópolis antiguas y al interior de los Estados nacionales que imponen una cultura homogénea sobre la diversidad. Frente al Estado homogéneo, Luis Villoro propugna por un Estado plural que reconozca e incluya la diversidad de identidades culturales que han sido "ninguneadas". Análogamente, frente al papel hegemónico de la cultura occidental, se sostiene el valor semejante de todas las culturas.

Luis Villoro ubica en las naciones latinoamericanas y en general en los países del Tercer Mundo que han sido excluidos de los beneficios del orden social, político y económico internacional, la persistencia de la diversidad cultural: las culturas de estos pueblos tienen ventajas importantes frente a la cultura occidental, que los convierte en los principales agentes o sujetos del cambio histórico a favor del pluralismo: ventaja como la prelación de la comunidad sobre el individuo y por tanto de la solidaridad sobre la competencia egoísta; prioridad de la diversidad frente a la exclusión; visión cosmológica de la unidad del hombre con la naturaleza, frente a una racionalidad dominadora, instrumental. Defensa de una democracia comunitaria (republicana) que articule la diversidad y procure el bien de todas las comunidades, Villoro sitúa en particular la construcción de este nuevo proyecto cultural y político en los pueblos y comunidades indígenas que han resistido 500 años de exclusión, 500 años de injusticia, y que ahora luchan por su emancipación y reconocimiento, como es el caso del movimiento del EZLN. 